\title{
Murillo Araújo y su Lirismo Purísimo
}

$\mathbf{E}^{\mathrm{N}}$

más de una oportunidad y por más de un crítico autorizado, Murillo Araújo ha sido considerado el mayor poeta brasileño contemporáneo. Claro que tal jerarquía resulta, en muchos casos, en muchos países, arbitraria y hasta injusta. Quizá en un ambiente de escasa producción pueda elegirse, en verdad, un primer poeta. Mas en un país de tal opulencia lírica como to es el Brasil actual, yo creo más acertado dividir ese título entre tres o cinco valores. Así, por ejemplo, es indudable que Murillo Araújo figuraría necesariamente en esa selección, junto a Jorge de Lima y a los otros poetas que, al enriquecer la lírica de su patria, están también entre los grandes poetas americanos. Hay muchos nombres para elegir: Tasso da Silveira, Murillo Mendes, Cassiano Ricardo, Manuel Bandeira..., La lírica brasileña contemporánea posee todos los matices, noblemente expresados, y es realmente una lástima que su valor no haya trascendido en los países hermanos del Continente, con la amplitud que se merece.

Murillo Araújo nació, en 1894, en Serro, pequeña ciudad del histórico y vasto Estado de Minas Geraes. Serro, fundada en la época de las primeras exploraciones de las minas auríferas, es una ciudad montañosa, de clima frío. En el poeta, que desde hace lustros: reside en Río de Janeiro, parece existir una como hermandad de las dos características de su ciudad natal y de la capital en que vive sus días: la rutilancia tropical está, muchas veces, como atenuada por cierta bruma de región montañosa. La fiesta de las imágenes deja espacio a una humildad cristianísima, voluntariamente desprovista de toda gala. Es poeta sobrio y rico a la vez, místico y humano, moderno y de todos los tiempos. 
Muy joven, sintió el llamado de su vocación. Su primer libro Carillones, aparecido en 1917, recogió tuna selección de sus poemas escritos desde la adolescencia. Ya en esas páginas se revela, como característica esencial, una gran pureza lírica. Diríase que al influjo de su poesía todo se anima, todo se transfigura, vistiéndose de nuevas galas, de luces nuevas. Esta virtud fué acentuándose en su segundo libro La ciudad de oro, aparecido en 1921. Trátase de un emotivo elogio a la capital carioca. Las dotes expresivas del poeta han llegado en ese libro a gran altura. Más de un crítico ha señalado, como lo mejor en ese poema todo bello, aquellas estrofas destinadas a evocar el pasado de Río, de Janeiro. Si bien en este estudio presentaré los poemas de Murillo Araújo en traducciones realizadas por mí, haré aquí una excepción, para transcribir una versión insuperable que el poeta y crítico boliviano Enrique Bustamante y Ballivián realizó, interpretando una de las páginas más significativas de $L a$ ciudad de oro. Héla aquí :

\section{CIUDAD DEL PASADO}

¿Rosas de oro y de amor, muertas y suaves rosas, en loor del pasado y sus sombras saudosas:

En barroco imperial, en barrios portugueses, al tono triste $\mathrm{y}$ viejo de las cosas de otrora, los despojos banales de edificios burgueses toman purpúreo tono, triste y glorioso a veces, en la hora del crepúsculo, cuando el poniente dora...

Memorias coloniales... Espectros de otros años, en que aún no deslumbrara la civilización.

¡Oh, a pesar de la edad, del tiempo y de los daños, cuán pintoresca es tu noble ancianidad, cuánto tu antigüedad, cuánto tu tradición!

Las calles nuevas tienen fachadas de ornamento, llenas de altanería. ¡Pero un alma sombría tienen las de convento. de tono ceniciento de canteria! 
¡Oh, en el desván sombrío y negro de las losas, cuántas vidas, mi Dios!

¿Qué hiștorias misteriosas,

cuántas risas de amor, cuántos llantos de adiós!

En estas viejas calles sin sol, ¡qué de añoranzas $y$ visiones de ayer, en casas arruinadas!

E1 Brasil colonial . . El reino... Los Braganzas. . iLas antiguas berlinas, las literas cerradas, y en el desfile, al sol, en un tropel de lanzas, Don Juan VI sonríe en su coche real!

Allá, en palacio antiguo, entristece y asombra una gloria de Inconfidentes;

y ora quizá, en la noche, silente, alba, la sombra de Tiradentes...

En el salón saudoso de aquel otro palacio entre figuras de una olvidada reunión, vaga el perfil anciano de José Bonifacio, de espadín y rabona, la cartera en la mano, grave y sereno, el gesto triste, el mirar lejano, en sueño de ambición...

En la Quinta Real surge en viejas alamedas Don Pedro, el Romancesco, en romancescos mantos, y a lo lejos sonríe entre rosas y sedas, Domitila, feliz marquesita de Santos. .

Suéñase, más allá, en añoso camino, la imagen de otro Pedro, el glorioso monarca... Y pasa... i Al aire tiemblan, cual pendones de lino, sus barbas imperiales, de ingenuo patriarca!

En obscuros desvanes, calles de tristes glorias, cuántas vidas, mi Dios, y sueños y memorias iamor, gloria, dolor y adiós!

Viejo burgo ancestral de casonas sin brillo, con fachadas banales de piedras y azulejos; jirones comerciales con casas de ladrillo aureoladas de sol, de llamas y reflejos; 
ciudad de antiguas casas con vaho de humedad, con el azul y suave moho de la saudad; duerme el sueño feliz del ansia, dulce, austera, a sombra de la edad...

¡Duerme... y serena espera!

¡Espera la gloria de alborada, el dia clato del risueño redimir, sonoro y nuevo, en que de tu sombra arruinada palacios de oro se han de erguir?

Seis años después de la publicación de La ciudad de oro, editóse La iluminación de la vida, obra en que el artista aparece cultivando un lirismo más imaginativo, más variado, más amplio. Por una de las más interesantes facetas de su personalidad, es Murillo Araújo un espíritu auténticamente brasilero. En La ciudad de oro ese sentimiento se expresa, sobre todo, en la tradición, en el buceo del pasado y en la mirada tendida al porvenir. En La iluminación de la vida, el paisaje verdeamarillo de la tierra soleada inspira muchas de las páginas más significativas, por ejemplo: "Soy un hombre del mundo joven", "La vida brilla", "Calle del cerro", "Sol", "Domingo". Siempre la emotividad es honda y fina, con gran sobriedad de medios expresivos y una amplia originalidad que no cae jamás en fútiles extravagancias. $\mathrm{Y}$ en lo que se refiere a la brasilidad de $\mathrm{Mu}$ rillo Araújo, comprobamos que - a pesar de estar reflejada, muchas. veces, de una manera objetiva - reside más bien en facetas espirituales. $Y$ es que Murillo Araújo, como todo verdadero poeta, tiene la virtud de sublimar la realidad, espiritualizándola. Por ejemplo: está en una broadcasting, recitando sus versos a los niños. Veamos: con qué fiesta de imágenes poemiza ese momento:

En esta estación de radio trasmisora,

la cámara del estudio

silenciosa

envuelta en las cortinas de terciopelo

toma sombras litúrgicas de altar.

Fuera, es un bronce el cielo mudo, una gran campana

con el péndulo de plata, lento y sordo, de la luna

que no se oye tocar... 
Sólo la noche murmura

el canto de los astros, milenar...

Aquí -en esta hora- un único ruido:

mi palabra - pájaro perdido- corre el mundo

veloz,

como un espejo mueve un relámpago al sol.

En lo alto de la antena, trémula, bermeja, pajarea una estrella

impaciente. .

y la palabra mudada en meteoro galvánico

salta eléctrica

volando

velocísimamente.

Grita en el bruhaha de las grandes capitales radiosas,

en los palacios lapidados,

entre los jardines que son pebeteros de flores,

o en los simples pesebres

de la masa humilde, masa admirable $y$ mansa;

$y$ abre en suelos anónimos mil gérmenes de tosas

y alegra, como Noel, con juguetes de estrellas,

cada cerebrito azulado de niño.

Canta en las tierras rústicas,

ya húmedas,

donde el rocío aureola a los labradores.

Susurra más allá de los laberintos del océano,

en la orla de los transatlánticos ligeros

en que se embarcó el viento,

y lleva un eco del convivio humano

a los marineros

en los jardines móviles y desiertos del agua en flor.

Más rápido que los viejos aquilones,

mi canto repercute en todas partes,

como un rayo poético

en un segundo.

Recorre las extensiones, omnipresente, imantado, magnético,

y entre todos los seres se reparte

mi corazón sonoro por el mundo. 
Como puede comprobarse por el originalísimo poema que acabo de traducir, este poeta sabe ennoblecer aspectos y detalles de la vida cotidiana que - por ser vistos continuamente-- acaban por parecernos vulgares e insignificantes. Aspectos y detalles que están ahí, siempre a la espera del artista que sepa darles la mano, iluminarlos. $\mathrm{Y}$ a propósito de esta virtud poética, creo que corresponde insistir en el mérito que tiene la poesía realizada con elementos tan humildes, elevados al plano de genuinas obras de arte. La mayor parte de la gente llama "prosaico" a lo que no está encuadrado en un estrecho marco de concepciones que se consideran "poéticas" y que -a final de cuentas- no son más que de un mal romanticismo. Temas gastados, repetidos al cansancio. No es posible insistir en ellos. No vale la pena, realmente, ponerse a cantar para volver a entonar las canciones que han perdido ya toda su frescura, todo su vigor. E1 verdadero poeta es siempre un renovador. Lo es, especialmente, por su manera de ver las cosas, por su "visión". Pero debe serlo, sobre todo, en su afán de dar vida lírica a lo que pasa inadvertido para quien no posee el sortilegio de la bondad poética, con caridad que rejuvenece el mundo, que purifica las almas, que hace reposar de tantas y tantas fatigas, que calma la sed de tantos labios.

En 1933 apareció un nuevo libro de este autor: Los siete colores del cielo, cuya bella portada presenta un delicado juego de colores. "Yo he creado para el hombre otro cielo: la infancia - y otra infancia: la poesia", dice bellamente en "Dios, poema de la vida humana, edición única", al abrirse este libro. De Los siete colores del cielo el poema que yo prefiero es aquel "Nacimiento del poeta", especie de sintesis de lo más representativo de este artista:

Era un muchacho pobre, vagabundo y transido de frío, un pequeño rapaz con la gorra caída sobre el rostro sagaz, y de remiendos esmaltado el pantalón, descalzo, de mirada ilusoria, ahijado de Nuestra Señora de la Gloria.

Un día de su cumpleaños (como siempre acontecía) llegó la noche sin traetle ni un juguete... a no ser la lunar luz de melancolía. 
$Y$ pensó el pobrecito:

"Si yo, en vez de madrina,

en el cielo un padrino tuviera,

tal vez en este instante un regalo me diera.

"San Jorge, por ejemplo, ¿no me podría dar su lanza, esa lanza alta y clara, de fulgor vencedor,

esa lanza de sol, que espantaba al dragón?

"Y San Luis, si quisiera, le daría

la corona, la corona de rey...

y con ella - ¿quién sabe?- la grandeza,

la riqueza,

el poder.

"San Sebastián

acaso le traería la coraza de oro celeste

angelical,

protectora en la peste,

defensora de toda enfermedad, dolor y mal.

Mas su madrina era Nuestra Señora de la Gloria... ¿qué le había de dar?"

...Y en aquella hora obscura

el muchachuelo vagabundo iba a llorar.

Iba, pero en ese instante

a su madrina vió llegar

llena de gracia, como en un sueño,

blanca, blanquisima de luz lunar.

Ella, en el cielo había oído aquel dolor del ahijado. iY ahora llegaba linda, linda, soniriendo

en un fulgor!

Recibió de ella el manto estrellado de luces.

$\mathrm{Y}$ tomando ese velo, el pobre muchachuelo tuvo para jugar las estrellas más puras del cielo. 
E1 niño Jesús

-que siempre abraza el cuello de Nuestra Sra. de la Gloria-

dió al muchacho la bola del mundo, que en su mano

traía.

Y el niño callejeto tuvo para jugar

todo el globo cristiano.

Tomando tierra y cielo por divinos juguetes,

el gury 1 vagabundo

de ojos de luz risueña, comenzó su cantar...

Y fué asi como un poeta más surgió en este mundo... para vuestro pesar.

Sí, "para vuestro pesar", repitamos con el autor de esta magnífica poesía. Para pesar de todos los que creen que el poeta -el verdadero poeta- es un ser extemporáneo, que vive fuera de la realidad de las cosas. Para pesar de todos los que no sienten que la vida sin poesía es bien triste y bien árida. Para pesar de todos los que no han comprendido aún que la poesía es la más bella manera de ennoblecer el dolor hasta llegar a transformarlo en placer.

El poema que acabamos de dar a conocer acentúa uno de los aspectos más personales de la poesía de Murillo Araújo: el católico. Presentado con toda sinceridad y pureza, dicho aspecto no llega nunca a constituir un tema insistente, de propaganda. Aunque el lector no comulgue con ese credo del poeta, no puede, sin embargo, dejar de reconocer la universalidad de su poesía. El catolicismo de Araújo, a pesar de sus fuertes raíces, aparece como una sutil veladura que afina los perfiles - a veces demasiado rudos- de la realiclad. Porque es también digna de todo elogio la riqueza de detalles realistas de esta poesía. Murillo figura entre aquellos autores que han sabido comprender bien el precepto de Amiel: "Cada paisaje es un estado de alma". $Y$ por eso pertenece al grupo de los líricos descriptivo-subjetivos. El paisaje enciende su inspiración, sus ojos captan toda la gama luminosa, sus ritmos fluyen entusiastamente frente a la Naturaleza, pero su fuerza emotiva, su honda espiritualidad, acaban por vencer al paisajista. Esta sensibilidad agudísima aparece en todas sus estampas: iqué lirismo altísimo en esa evocación del abuelo zapatero que trabaja y trabaja, contento porque está terminando el zapatito para la Navidad de su nietecito! $\mathrm{O}$ en la tragedia 
de aquel niño que remontaba su cometa y que fué muerto por un auto que pasaba. Pero luego "Dios recogió su alma, como otra cometa, tomada por el hilo de un rayo de sol". O en aquel recuerdo tan grảcil, de infancia brasilera:

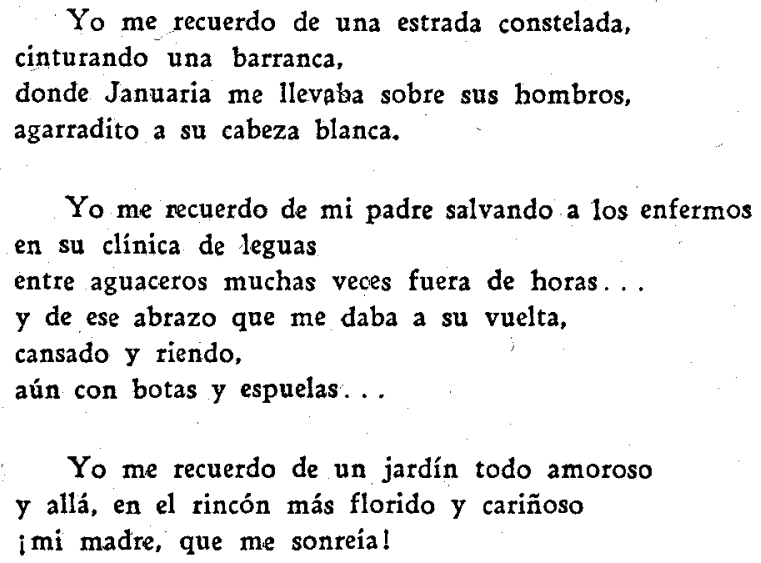

Deliciosa de pureza es la "Historia cristiana": el niño Jesús que en la noche de Navidad lloraba, no quería adormecerse. Nada, ni la cantilena del órgano conseguía servirle de arrullo. Hasta que al fin fué una negra humilde y descalza la que lo tomó en sus brazos, le cantó con ingenua dulzura. $\mathrm{Y}$; oh milagro! el niño Jesús sonrió y adormecióse. En esta página, como en otras muchas de Araújo, admiramos su elogio de los seres humildes.

En lo que se refiere a los medios expresivos, ya hemos visto que su estilo se caracteriza, sobre todo, por su sobriedad, pureza y diafanidad... Sobriedad, pureza y diafanidad que en ningún momento dejan de ser riqueza, riqueza sintetizada, condensación intensa, como la gota de esencia que resume, en su brevedad, toda la opulencia de cien rosas que murieron para darle vida.

El léxico de este artista es muy personal. Los adjetivos adquieren muchas veces un nuevo significado, se visten de galas nuevas, adquieren nueva vida. Lo mismo puede decirse de sus ritmos, que he tratado de conservar en mis traducciones. No son los ritmos antiguos, tan ceñidos, tan monótonos. No son los llamados ritmos modernos, cuya excesiva libertad los acerca a la prosa. Es una feliz unión de lo buteno de ambas tendencias. $\mathrm{Y}$ es, sobre todo, una mu- 
sicalidad que sigue fielmente la marcha de la emoción y del pensamiento. Ciertamente, un seguro instinto musical guía la creación de esos ritmos, $\tan$ personales.

Murillo no ha querido renunciar totalmente a la rima. No la usa con la obligada asiduidad de los clásicos, pero sabe que la rima es una de las características propias de la poesía. La utiliza, no como la melodía fácil y tintinante, sino como el eco puro y fraterno, como el són que une y funde las ideas y sentimientos afines.

Historiando la moderna poesía brasileña, el crítico Edison Lins afirma que algún libro de Murillo Araújo sé resiente "de exceso de colorido y de escenario, de efectos de onomatopeyas y de ritmos". Tal apreciación me parece precipitada. Sin duda, se refiere al libro La iluminación de la vida, el más estilizado de este autor. Mas su colorido y su escenario no llegan nunca a ser exceso: siempre están unidos a una sobriedad depuradora, a un sentido estético que sabe limar las aristas innecesarias. Dije que en su poesía hay siempre como la presencia del clima frío y montañoso en que nació este poeta, y de la gloria tropical de la urbe en que reside. Además, si bien es cierto que en el libro La iluminación de la vida es donde Araújo se expresa con más riqueza de imágenes - llegando, en algunos casos, a ser casi sobrerrealista-, nunca esa opulencia imaginativa debe ni puede confundirse con el simple juego metafórico. El lenguaje de imágenes es uno de los más nobles medios de que dispone el poeta para decir su mensaje. El poema que ha estado viviendo en lo más hondo del corazón, surge pleno y desbrozado de impurezas, reducido a sus líneas esenciales y sublimado en la belleza de las imágenes, que son, muchas veces, lenguaje de emoción y de música. Todo verdadero poeta lo siente así. Todo verdadero poeta lo sabe así. Es la estilización necesaria para dar al poema la voz propia, para hacer de él una simbología viviente. En cuanto a las onomatopeyas usadas por Araújo, es sobre todo en su poema "Tonada del negro en el banzo" - - una de sus obras maestras- donde ese uso se manifiesta con más intensidad. Precisamente, por ser intraducibles muchas de tales voces onomatopéyicas -así como muchos de sus vocablos regionales- lamento no poder ofrecer una versión de esa "tonada" que figura junto a las mejores páginas americanas de poesía negra, que el gran compositor brasileño Haeckel Tavares musicalizó noblemente y que ha sido grabada en discos y 
figura en el repertorio de casi todos los programas de música brasileña moderna.

La emoción - una emoción limpia y noble- es presencia constante en la poesía de Araújo. Emoción depurada, con claridad de niño y melancolía de hombre. Emoción que hace pensar en la acertada afirmación de la inolvidable Alfonsina: "el poeta es una antena sutilísima, que recibe voces que llegan no sabe de dónde y que traduce no sabe cómo".

En 1940, Murillo Araújo regaló una sorpresa a sus admiradores: el libro Estrella azul. La sorpresa está en el subtítulo: "Poemas para niños". Y sin embargo, ¿de qué otro poeta brasileño debía esperarse un libro así, todo lleno de juego, de luz feérica, de música finísima, de rondas, de lunas, de pajaritos, de ángeles, de rosas, de cajas que guardan tesoros fabulosos? Ciertamente, en La estrella azul Murillo nos daba su primer libro para los niños. Pero ya - sin habérselo propuesto- había sido poeta para los niños, en algunas páginas de sus libros para hombres: en "Nacimiento del poeta" -cuya versión ofrecí-, en "Los dos papagayos", en "Historia cristiana", en "Infancia brasilera".

¿Y la deliciosa explicación con que el autor inicia su libro? "Compuse mi poesía para la infancia. La poesía de la infancia, fué Dios, sólo Dios quien supo escribirla."

Araújo poeta es tan musical, que hasta ha escrito música para algunas de sus canciones - música que incluye en Estrella azul. Es muy linda la que acompaña estos versos:

Canta, canta pajarito en el rosal del camino, el rosal en que te ví.

Canta, canta en tu nidito, pajarito, pajarito, canta alegre: "ti-tiu-i".

Duerme, duerme, pajarito en buena cuna de armiño, con tu sonrisa feliz...

Duerme, mientras con cariño 一pajarito, pajaritotu madre vela por ti. 
Las páginas de La estrella azul constituyen la exaltación de todo cuanto la vida tiene de puro $\mathrm{y}$ noble, de fino $\mathrm{y}$ bienhechor. La crítica que puede hacerse a la poesía hispanoparlante -en lo que se refiere a la falta de buenos libros de poemas para niños- es también aplicable al Brasil. Pareceria que en estos paises de América no se ha comprendido todavía cuánto se ennoblece el artista que pone su inspiración al servicio de la infancia, tratando de llevarla de la mano para una mayor comprensión de ese maravilloso mundo que la rodea y en que sus ojos se abren asombrados, necesitados de la voz del poeta para realizar una como ordenación y explicación de las cosas. En los países de más densa cultura - Inglaterra, el norte de Europa, Estados Unidos- es bien visible que los poetas han sabido hablar a los niños, a veces sin proponérselo, es cierto (sería, en Estados Unidos, el caso de Carl Sandburg y Amy Lowell). Y si en algún país del Sur - la Argentina- se empieza a comprender la necesidad de un lirismo para los niños, todavía se está muy lejos de llegar al ideal, pues por un sólo libro de ese género aparecen ciento en que se repiten incansablemente los temas de interés personal. La estrella azul es, a mi juicio, el mejor libro de poemas infantiles aparecido en el Brasil. En sus estrofas, la musicalidad se ha agilizado, tomando esa gracilidad despreocupada y feliz que es uno de los mayores encantos de las tonadas populares brasileñas, de sus cantares anónimos. $i \mathrm{Y}$ es que el folklore de ese país hermano es $\tan$ hermoso, $\tan$ rico, $\tan$ variado! Cuando se estudien detenidamente sus danzas, sus leyendas, sus poesías, América entera tendrá una revelación. Es un tesoro escondido en la mina de los pequeños pueblos, al pie de los "morros", junto a los ríos ondulantes, en el bello desorden de las junglas. Murillo Araújo, en muchos de los poemitas de Estrella azul ha sabido re-crear la gracia niña de esas canciones que están en la boca y en el corazón del pueblo. Gracias le sean dadas por tan digna labor.

$Y$ en el año de 1941, el tomo La escalinata encendida viene a marcar el ascenso triunfal de la poesía de este autor: en sus páginas, el poeta ha llegado a su plena madurez. Su mística cristiana y su mística de la poesía se abrazan y se iluminan en este tomo, de una mística humana que parece condensar toda la obra del poeta.

Un magnífico credo abre el libro: "Creo en la Poesía, indispensable en la Vida. Creo que el mundo es un texto con imágenes de Dios. Creo que el stueño divino anima todas las cosas, y el sueño 
humano ilumina al ser ya animado. Creo que el hombre necesitará siempre de la Poesia, del sentido poético, que es heroísmo, altruismo, devoción y amor - de todos los sublimes líricos que son el lenguaje de Dios; y de la forma poética - la idea en cadencia y armonía- porque el ritmo es ordenado, viene de un orden la existencia y si un caos se organiza interrumpe la vida. Creo en la Poesía, alma eterna del mundo... en la Poesía esencial, en la Poesía santa, en esa infancia del espíritu, rociada de estrellas, en la Poesía piadosa, que se inclina fraterna sobre los pobres destinos, y que desde el cielo extiende, para nuestras angustias, una escalinata encendida".

Si bien en La escalinata encendida (o "iluminada", pues ambos calificativos traducen el vocablo del título original $A$ escadria acce$s a)$ el poeta conserva las virtudes que lo señalaron con voz inconfundible en el coro de sus hermanos, es indudable que se advierte también cierta evolución y superación en lo que se refiere a una mayor intensidad emotiva y expresiva. Al mismo tiempo, logra una más acentuada riqueza conceptual, debiendo aclararse que jamás el concepto aparece en su fria exposición filosófica, que nada tiene que ver con la auténtica poesía. Precisamente, porque es Araújo un imaginativo y un músico, resulta admirable cómo su imaginación y su sentido del ritmo se unen para dar, en su visión y en su musicalidad, toda la tremante belleza y hondura de un pensamiento que, al afinarse en la expresión lírica, parece hacerse más profundo. En La escalinata iluminada la poesía - y el misticismo- de este brasileño toma un sentido cósmico, ya en parábola de belleza suma, ya en poemas que son a manera de himnos. Siempre dentro de esa multiplicidad de inspiración que se une por virtud de una vigorosa individualidad estética. Estos poemas se toman de la mano, llenos de amor, como una familia de seres humanos: vemos la canción delicada y pequeña, que es a manera de una niña rubia; el poema sinfónico, estremecido de fe y de dolor, que se diría un fuerte mozo pletórico de esperanzas renovadas; todo lo que es humano, en el más alto sentido del vocablo, vive y alienta en esta poesía, friso iluminado por la bondad del artista. Su optimismo es una nota constante, aun en aquellas páginas que parecen más amargas. Es el optimismo de quien conoce el dolor y no lo teme. El optimismo de quien tiene una fe. De quien ama este mundo y ama el mundo que se abre tras la muerte. El optimismo de quien puede repetir, como Tagore: 
"Cada niño que viene a la vida, nos dice: Dios espera aún del hombre". Y que sabe que el hombre no defraudará esa esperanza, el día en que sepa comprender la bondad de la belleza. Hay a manera de un sinfonismo vital en esta poesía que tanto se extasía en el pequeño rincón florido, como se eleva en un revuelo gigantesco en busca de las estrellas con que mira la sombra nocturna. Junto al canto "de esperar el sol" o "de la hora salvaje", "de la playa feliz" o "de la mañana bulliciosa", está el "canto de todos los gemidos", "de todos los calvarios", "de todos los caminos", "de la luna de lágrimas". ¿Por qué no? El poeta integral debe ver la vida cara a cara, con sus sonrisas y sus lágrimas. Una visión totalmente risueña resulta tan falsa como la que sólo busca la sombra. Lo que importa, en suma, es el valor de renovación, de esperanza, de fuerza, de sabiduria que el poeta logra extraer de las horas amargas. La poesía de Araújo es optimista, anchamente optimista, en la emoción que se desprende de su conjunto y de las enseñanzas que nos deja, porque al no ocultar el dolor, es ella misma como el talismán para vencerlo. Tanto sus poemas esquemáticos como aquellos de delineadas alegorías nos hablan de un mundo mejor $\mathrm{y}$-sobre todo- de una fuerza para embellecer este mismo mundo de nuestras luchas, de nuestra terca sed de justicia.

"Sólo es digno de la libertad quien la conquista día a día", dijo Goethe. Podría también afirmarse que "sólo es digno de la belleza de la vida quien día a día trata de levantar el velo que la cubre, es decir, de conquistarla".

Una poesía como la de Murillo Araújo es como un nuevo mundo, no ajeno a éste, pero sí sublimado por la magia de la belleza. Nuevo mundo del que se retorna al habitual, con nuevos bríos y renovadas energías para seguir en la lucha diaria. Porque ésta es, sobre todo, la gran obra, el gran beneficio, la eterna trascendencia de la poesía: limpiarnos del cansancio cotidiano, redimirnos de todo sentimiento negativo: rencor, desaliento, escepticismo. Volvernos a la vida con los ojos límpidos de los niños, donde el porvenir dibuja paisajes multicolores.

$\mathrm{Y}$ entre los realizadores de belleza que nos hacen este bien, está Murillo Araújo, el artista que vive en nuestros días, que vive en nuestra América, al pie de una montaña en cúya cumbre un Cristo, de cara a la aurora, abre sus brazos consoladores y protec- 
tores; Murillo Araújo, cuya poesía ha sido tan bien definida: "diáfana, intuitiva, integral. Sin preconceptos antiguos. Sin preconceptos modernos. Con el lenguaje total de los niños. Con el alma entera sonando en el timbre que Dios le dió".

\section{Gastón Figueira, Monievideo.}

1 Guty.--Voz indígena, utilizada en el Paraguay y en algunas regiones de Brasil, Uruguay y Argentina, para designar a un niño no mayor de unos catorce años. 
